\title{
Rethinking Pro-Active Disaster Planning in the Workplace: The Case of a Selected Mine in Zimbabwe
}

\author{
Langtone Maunganidze ${ }^{1}$, Farai Ncube $^{2} \&$ Peter Sibanda $^{2}$ \\ ${ }^{1}$ Department of Sociology, University of Botswana, Gaborone, Botswana \\ ${ }^{2}$ Department of Human Resource Management, Midlands State University, Gweru, Zimbabwe \\ Correspondence: Langtone Maunganidze, Department of Sociology, University of Botswana, Gaborone, \\ Botswana. Tel: 267-7557-7199. E-mail: langtone.maunganidze@mopipi.ub.bw/lmaunganidze@gmail.com
}

Received: April 18, 2013

doi:10.5539/ijbm.v8n15p90

\author{
Accepted: May 25, 2013 \\ Online Published: July 12, 2013 \\ URL: http://dx.doi.org/10.5539/ijbm.v8n15p90
}

\begin{abstract}
In the history of the mining sector in Zimbabwe, one occupational disaster that evokes sad memories is the 6 June 1972 Kamandama incident at Hwange Colliery Company that claimed 427 miners. One of the challenges confronting the mining sector is capacity to prepare for such uncertainties and complexities. Events such as the rescue of trapped miners in Chile, and the recent Zimbabwean Platinum mine case in which 78 workers were trapped underground although successfully rescued are one of the few cases that have brought about a heightened global consciousness of the need for effective disaster and crisis management practices. This paper explores the nature and extent of the emergency or disaster preparedness of mining sector in Zimbabwe using the case of ABC mine's (not its real name) experiences and practices. The study which is influenced by postmodernism, adopts a predominantly qualitative research design. It uses a mixture of both primary and secondary data. The paper's central argument is that contemporary pro-active planning processes have limitations in as far as helping companies cope with the complex challenges such as disasters or emergencies. Emergencies and disasters are relatively 'wicked' problems which may only be managed by use of 'post-normal' planning strategies. In a world of such complex and shadowy possibilities organizations do not know if their strategies are appropriate or what consequences might be. The idea of 'pro-active' planning is a mirage that only serves to perpetuate the illusion that risk to workplace disasters is controllable or manageable. Overall, most of the prevention, response and post- recovery initiatives, are effectively managerial devices or representations to enhance the reputation of the organization.
\end{abstract}

Keywords: occupational health, emergency, disaster, post-normal planning, post-modernism

\section{Introduction}

Occupational hazards and disasters threaten the integrity, reputation and ultimately the viability of a company. Recent events that include the September 11 US terrorist attack, the Chilean mine rescue mission, the 2012 South African 'Marikana' mine wildcat strikes that resulted in the death of 36 miners and the Zimbabwean case at a platinum mine in which 78 workers were trapped underground and successfully rescued have brought about a heightened global consciousness of the need for effective and pro-active disaster and crisis management procedures in the workplaces in general and mining sector in particular. This article examines the nature and extent of the emergency or disaster preparedness experiences and practices at $\mathrm{ABC}$ mine (not its real name) and in particular revisit the utility of the proactive planning paradigm. Proactive planning in disaster or crisis management in general is not a new phenomenon and extant literature is replete with studies on the approach (e.g. Beck, 1992, 1994; Cannon, 2000; Fischer 111, 2001; Baranger, 2002; Blythe 2004 and with some taking postmodernist approach (Browning \& Shelter, 1992; Cronon, 1995; Sim, 2001). They however do not specifically focus on occupational disasters particularly in the mining sector and this article is a timely intervention.

Nobody expects an emergency or disaster, especially one that affects them, their employees, or their company, and yet in real life emergencies always occur. One of the challenges Human Resources and SHE managers face in the mining environment is ensuring the existence of pro-active approaches to manage the health and safety of employees at the work place in the event of an emergency. Indeed as part of an effective proactive approach to managing employee health and safety a contingency plans and the necessary supporting structures to deal with 
any emergency are required.

\section{Background}

As earlier observed accidents do happen no matter the preventive or post-hazard management strategies that are in place. Notably the most critical aspect is to have a proactive approach in place to at least mitigate in times of emergencies. Swanepoel, Erasmus, Van Wyk and Schenk (2003), suggested that one of the most important elements of a proactive attitude towards employee safety and health is to establish adequate contingency or emergency plans and procedures cater for a variety of eventualities such as fires, bomb threats, and explosions. Indeed the safety of employees in organisations is very critical for the success of a company and as such it becomes crucial for companies to have pro-active measures in place to deal with emergencies. There is now both a business and moral or political case for companies particularly in the mining and manufacturing sectors to have contingency plans in place to deal with accidents. These plans are not uniform in any way but are company specific entirely depending on the nature of the workplace. This study provides a rethinking to the proactive approaches adopted at $\mathrm{ABC}$ Mines and how they are or can be a learning template for the organizations in similar circumstances.

\subsection{Overview of the Mining Situation in Zimbabwe}

The total land area for Zimbabwe is $391000 \mathrm{Km} 2$. and has abundant mineral deposits that are sparsely spread. The mining industry in Zimbabwe forms the bed rock of the economy, with the state relying heavily on mining which according to the Zimbabwean Fact Sheet of 2010 contributed 20\% to the nominal GDP pegged at US\$6 billion providing unparalleled contribution towards the socio-economic development of the nation. According to the same source 2010 estimates for the annual export receipts were pegged at US $\$ 2.3$ billion, with $65 \%$ coming from mining. The mining sector in Zimbabwe employs more than 65000 employees the (Zimbabwe Chamber of Mines, 2010). Considering that Zimbabwe has one of the best platinum deposits in the world, a study that focuses on this area becomes crucial. Indeed the bulk of these employees are employed in three platinum mines; Unki, Mimosa and Zimplats, (all foreign owned) and other who employ a considerable number of employees, and as such both the government and communities equally rely heavily on them for employment creation and revenue generation through taxies pegged at $15 \%$ Value Added Tax (VAT) and 25\% Corporate Tax. With this background in mind it becomes clear one cannot ignore safety and health concerns to both employees and the company. In terms of royalties gold contributes $4.5 \%$, platinum $5 \%$, precious stones $10 \%$, base minerals $2 \%$ and $1 \%$ for coal. In Zimbabwe mines play a crucial role in the economy by paying $25 \%$ Corporate Tax, $15 \%$ Value Added Tax (VAT), personal income tax (PAYE).

To ensure maximum safety in Zimbabwean mines the Chamber of Mines works with quasi-government organizations such as National Social Security Authority (NSSA), Environmental Management Agency (EMA) and Labor bodies to ensure that mining operations cause no harm or injury to those working in mines. Emergency do occur mostly when people do not expect them. Historically the most touching emergency in Zimbabwe occurred at Hwange Colliery in 1972. On this fateful day Zimbabwe was struck by the worst tragedy ever experienced at the workplace, the famous Kamandama accident on 6 June 1972 at 10am. 427 miners perished following methane gas explosion at No 1 Mine Shaft. Recently in 2012, at Mimosa Mine 78 employees were trapped and successfully rescued unhurt. This resulted in national calls to reinvigorate the operations of the Mine Rescue Association of Zimbabwe, which although in existence since 1970s had been relatively dormant. Its mandate was to coordinate mine rescue activities throughout the whole country and its work being coordinated through the Mine Rescue Working party. This working party brings together the Chairman appointed by the Association of Mine Managers of Zimbabwe, zone coordinators, the national trainer, the national coordinator, a representative of the Chamber of Mines and a committee member.

Currently there are three platinum mining sites in Zimbabwe of which $\mathrm{ABC}$ is one of such. They have a combined production of approximately 188000 ounces per year. Five other platinum projects are at different stages of resource identification. In addition to gold, the platinum industry has the greatest prospect for immediate development. The following graph indicates the development of platinum production statistics over the years, as provided by the Zimbabwe Chamber of Mines. 


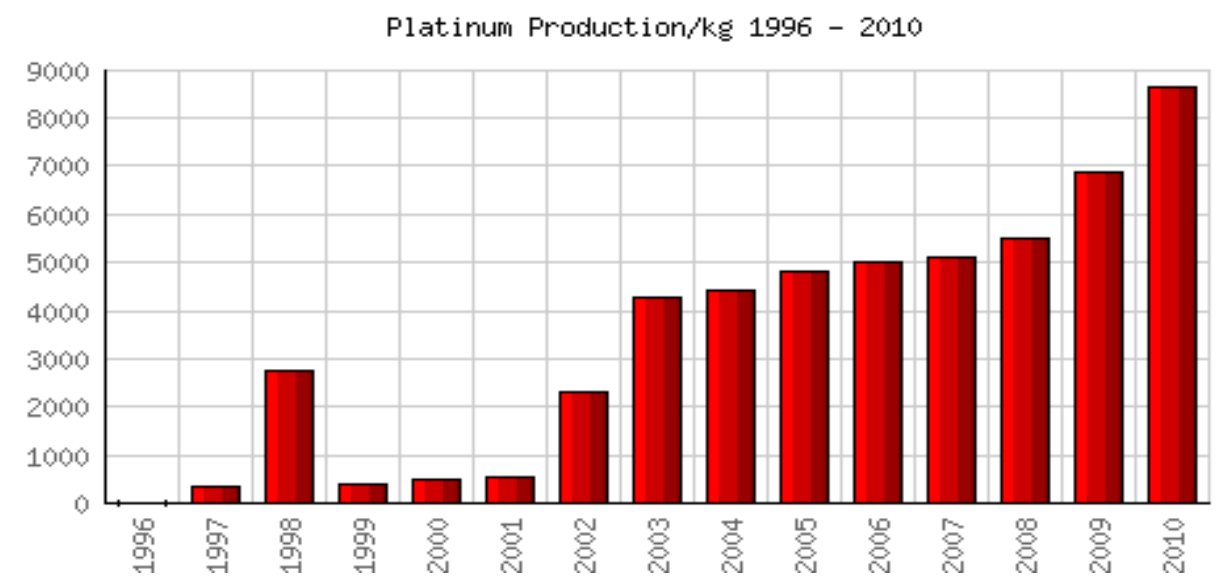

Figure 1. Platinum production in Zimbabwe 1996-2010

Source: Chamber of Mines Zimbabwe (2010).

\subsection{Occupational Health and Safety Performance}

The overall statistics for the industry make sad reading. According to the NSSA Annual Statistics Report (2010), the total number of injury claims received was 4143 . Interestingly and pertinent to the subject under study, the industrial sector with the highest number of claims received was mining with 458 cases of injuries, with 448 injured male colleagues and only 9 female employees. Fatal injury frequency (FIF) for the year was 90.4111 serious injuries with 75 fatalities were also reported in 2011. Since the figures are based only on claims received by NSSA there could be some under-reporting since not all workplaces espouse responsible reporting on issues of occupational health and safety.

Table 1. The accident statistics in Zimbabwe from 1997-2011

\begin{tabular}{|c|c|c|c|}
\hline Year & Total Reported & Person Killed & Person Injured \\
\hline 1997 & 43086 & 1307 & 17906 \\
\hline 1998 & 56433 & 2152 & 25984 \\
\hline 1999 & 51219 & 1858 & 23722 \\
\hline 2000 & 40316 & 1433 & 18105 \\
\hline 2001 & 39841 & 1399 & 18153 \\
\hline 2002 & 41753 & 1871 & 20419 \\
\hline 2003 & 78481 & 3549 & 37144 \\
\hline 2004 & 37596 & 1771 & 17577 \\
\hline 2005 & 36390 & 1291 & 18531 \\
\hline 2006 & 29250 & 1037 & 13819 \\
\hline 2007 & 21092 & 1127 & 10378 \\
\hline 2008 & 16904 & 1149 & 10427 \\
\hline 2009 & 20553 & 1576 & 12354 \\
\hline 2010 & 26841 & 1796 & 14336 \\
\hline 2011 & 30985 & 2001 & 15305 \\
\hline
\end{tabular}

Source: Safety and Health at work (SHAW) 2012.

Given such a background the interest in developing contingency plans to deal with emergencies becomes more compelling for authorities now than before. According to the 1988 International Labour Organisation (ILO) on major hazard control, emergency plans require that the workplace be assessed for the range of accidents that could take place together with how they would be tackled in practice. As such the area of emphasis is on developing both onsite and offsite emergency plans. The offsite emergency plan will have to link the possible accidents identified at the workplace, their expected likelihood of occurrence and proximity of people living and working nearby. As such emergency plans must equally identify organizations whose help will be required in the 
event of an emergency and must ensure that they were aware of their expected roles.

\section{Theoretical Framework}

\subsection{Rethinking Pro-Active Disaster Planning}

Configuration logic indicates that high performance results from a strong external fit between the firm's overall strategy and its environment, and a tight internal fit among capabilities, structures, processes and management (Delery \& Doty,. 1996). However one of the challenges confronting organizations particularly those in the mining sector is how to plan for uncertainty and unpredictability such as emergencies and disasters. This article is influenced by postmodernism and advances the argument that disaster preparedness or recovery plans which organizations present as a 'proactive planning' are predominantly post-normal (Sim, 2001a). They are actually a product of complicated discursive practices or system of representations, social and material practices, laws of discourses and ideological effects (Burr, 1995; Castree \& Braun, 2001; Fischer, 2003). Investing in disaster preparedness makes both business and social sense. The purpose of a strategy is to ensure organizational success and as Mintzberg (1994) argued strategy emerges over time as intentions collide with and accommodate a changing reality. Planning is not rational and objective but subjectively rational and directed towards attainment of desired outcomes (Carter \& Jackson, 1996). The so-called strategic actions are a form of 'systematically distorted information aimed at reifying, manipulating and politicizing communicative act that is shunted into the creation of consensus (Habermas, 1982; Lyotard, 1984; Pettigrew, 1977). Strategy assumes predetermination and stability or normalcy; the prediction of and forecasting of an acquiescent environment. Such an assumption is toppled in a fluid and changing environment in which uncertainty and ambiguity reign (Sim, 2001a). Disasters particularly in the mining sector are complex emergencies and preparing or planning for them is very difficult. Pro-active planning suggests a case of rational decision making process and which becomes dwarfed when it comes to dealing with arising risks and possible unintended consequences. Concurrent high levels of uncertainty with respect to the precision with which variables or situations can be measured are also a problem (Baranger, 2002). Emergencies have three characteristics; complexity, chaos and entropy (degree of disorder) (ibid), and their multiple interactions render proactive planning invalid or fragile.

Contemporary strategic planning processes do not help companies cope with the complex challenges such as disasters or emergencies. Emergencies will always occur no matter how prepared a company may be. They are 'wicked' problems which can't be solved but probably 'tamed' and will require some form of 'post-normal' thinking/planning (McCarthy, 2000). Wicked problems require non-traditional processes because they often have no precedents. In a world of complex and shadowy possibilities organizations do not know if their strategies are appropriate or what consequences might be (Camillus, 2008). Managers and other organizational actors have little control over the nature of mishaps (Orlikowski, 2002). The social construction of emergency managers as controlling and commanding is false ideology. They are not in control of anything. As Fischer 111 (2001) puts it; the managers command little and control nothing. What perhaps they can control is the capacity to present these 'disasters' and related plans as manageable and controllable.

\section{Methodology}

The study which is influenced by post-modernism, adopts a predominantly qualitative research design. It uses a mixture of both primary and secondary sources of data. The research is carried out in the form of a case study of $\mathrm{ABC}$ Mines, a platinum producing company based in Zimbabwe. Content analysis of company documents that include companies' annual reports, health and safety policies and procedures in the mining sector, on site-observations, and media reports. Data analysis techniques used were a combination of illustrative and ideal type methods (Newman, 2007). This was effective in confirming the assumptions and ideal characteristics of proactive/contingency vs post-normal planning as shown by data from content analysis and the selected thematic frames which are drawn upon and are central to the discussion section of this article. The analysis is based on the findings drawn from this content analysis of the company documents complemented by observations and selected lived experiences of the researchers and key informants.

\section{Discussion}

\subsection{Motives for Proactive Planning: Business or Political Case?}

According to results of a content analysis performed on the company's official records some of the company's strategic objectives were promoting employee safety and health, creating and sustaining mutually beneficial relations with employees and attracting, retaining and developing talent and skills. Ensuring the safety and health of employees, contractors and suppliers was essential if the company was to respect their most fundamental human rights. Consequently, without a meaningful commitment to respecting the rights of those 
with whom it interacted, the mine would have no social or political licence to operate. It is our contention that organizations can use employee health and safety performance as leverage for optimal and sustainable returns on their investment. For this organization employee safety is a key to business's operations and therefore places emphasis on a 'zero-harm' target. The company's ability to demonstrate disaster preparedness and concern for both workers and community enhances its reputation internationally. Group and site-specific HSE policies, procedures and standards were set, with the aim of ensuring that activities comply with legislative requirements both local and international particularly commitment to ISO 14001 Certification -aligned environmental management. Both offsite and on-site emergency plans were fully integrated into the overall Group strategy. The company argues that the setting up a disaster or crisis management team which regularly utilized risk reporting processes such as Strengths, Weaknesses, Opportunities and Threats (SWOT) and the development of company-wide emergency operations plans (EOPs) or business continuity plans (BCPs) would build greater consensus and legitimation. As seen in the aftermath of the Marikana disaster in South Africa workers issues tend to rapidly escalate from a crisis. Low morale, fear or mistrust lead to employee disengagement and reduced productivity. HR plays a strategic role in organizational sustainability to contribute tangible deliverables through advance training, including safety and health initiatives, leadership development, training, talent management and solid communication plans to support crisis management and disaster preparedness (Lockwood, 2005). Visible crisis management, response and recovery efforts by management are essential in reducing industrial conflict and helping employees achieve a sense of normalcy (Blythe, 2004). HR as both business partners and change agents have a strategic role and responsibility to ensure their organizations are aware particularly of the human side of a crisis and plan ahead to minimize its effects. Employees need assurance of safety as well as rapid return to productivity (Hiles, 2004).

\subsection{Deconstructing Proactive Planning and Health and Safety Practices}

Strategies that address the safety, security, health and welfare of employees before, during and after the emergency or disaster are tangible deliverables that make the crisis or emergency less wicked. At ABC there are various employee assistance programmes (EAPs) such as Children Welfare and Education Assistance, Medical Aid, and Housing. Most of them indicate that the mine offers more than what is required either statutorily or as part of industry-wide collective bargaining agreements. Apart from the image of the company being enhanced, we know that the real benefits of crisis management and business continuity planning are better avoidance of liability actions, protection of assets through risk reduction, protection of markets by helping to ensure supply and reputation protection, and compliance with health and safety legislation (Hiles, 2004). The organization views these activities as part of proactive or contingency planning. Reference can be to a similar case when some miners were trapped in the mining shaft and rescued. Management said that such 'near misses' provided them and the whole platinum industry an opportunity to prepare for any future recurrence. However, viewing this as the script for the future will be illusionary as emergencies are inherently 'wicked' and increasingly complex! So what is the logic of planning for disaster? Borrowing from Derrida (1981), we begin to discern that, "what is organized and representable can be set out in advance for control and manipulation. In this process, a deliberate form of suppression occurs which remains hidden and inexplicable (Chia, 1996: 145). Strategy formulation is value laden and thus the development of pure plans, untainted by practical concerns, is a mirage. Both the problem; disaster preparedness and the strategic possibilities to deal with it are 'wicked'.

The company places great recognition to the role played by health and safety in ensuring sustainable productivity. According to the ABC mines's Sustainable Development Report (2012) the company was committed to making safety a strategic deliverable that enjoyed greater weighting in manager and supervisor incentives. For example, targets such as : $20 \%$ improvement in Lost Time Injury Frequency Rate (LTIFR) and Fatal Injury Frequency Rate (FIFR) at each operation; 100\% compliance with road behaviour; and 100\% compliance with Platinum Rules or $100 \%$ disciplinary action for non-compliance; are set and supposed to be met as rule across the mines in the Group. Although there is a steady decrease in both the LTIFR and FIFR, the authorities maintain that there was still need for improvement. ABC's current disaster response or recovery initiatives are guided by the overall Group Strategy and we argue these are not necessarily proactive but only an attempt to achieve a vertical fit as required. For example it was observed that there was a lack of independent safety culture. Safety practices across the organization were only followed when effective supervision was present and demanded. This is paradoxical given that at all mine sites both employees and workers participated in the emergency response planning processes. There was no evidence of employee commitment and this negatively impacted on the organization's vision of 'zero-harm' across the Group. Consider the following comments from Chief Executive in his 2012 Report: 'The capacity of managers and frontline supervisors to effectively deal with people issues and re-capture the hearts and minds of our workforce is perhaps our most 
pressing business challenges'. This apparently came as a result of the six-week illegal strike in 2012, which rocked some of its sister company operations in neighboring South Africa which was characterized by intimidation and violence claiming four deaths of miners. At ABC mine in Zimbabwe there have not been any recent official reports of strike action.

Disaster preparedness at $\mathrm{ABC}$ Mine is not a result of 'self-organization' but an outcome of 'structural coupling or congruent change' (the structure of a system and environment both change as a result of iterative, mutual and non-destructive change) (Dempester, 2000; McCarthy, 2003). Planning for disaster is planning for something abnormal! For example, what would happen if disaster strikes emanating from area designated: 'EMERGENCY ASSEMBLY POINT'? What about if disaster replicates the recent South African 2012, 'Marikana 'case? Such a project lies in the domain of 'post-normal' science (Funtowicz \& Ravetz, 1993). Post-normal science thinking views all planning as a human construction and one that requires constant, critical review. Planning in the form of a disaster preparedness strategy may not only be illusory but a form of representation or ideology (Pettigrew, 1977; Chia, 1996). The belief in the existence of organizations as concrete, stable and identifiable free-standing entities with distinctive boundaries obscures and distorts our understanding of strategies (Hassard \& Parker 1993; Chia, 1996).).

The ' $100 \%$ disciplinary action for non-compliance' may not effectively transform the current measured culture of dependence to independence. This may be a traditional approach in dealing with 'wicked' problems' as there would always complex scenarios whose definitions would be a result of negotiation between actors and invoking multiple meanings. Definitions such as 'disasters', 'hazards', 'accidents' are a result of political negotiation, constituting an exercise of power. Pro-active or contingency plans are only effective to the extent that they are designed to handle events or incidents that are socially constructed. They are just a figure, human construction, artifact or displacement (Castree \& Braun, 2001). For example, what are the meanings of expressions such as such 'died in a fall of ground accident' (which appears the most common), 'died from drowning in shallow water', 'and died in an accident dealing with explosives' (SDR 2012: 50). What really is an 'accident'? What also constitutes disciplinable 'accident'? These are indexical expressions (Garfinkel, 1967) that should be understood in relation to the context of their production. 'Nature' cannot pre-exist its construction and has a rhetorical place in the politics of 'natural' disaster or 'mishap' discourses as instruments of power and control. The expressions serve to portray a sense of consensus and legitimation thus limiting possibilities for further interrogation. The definitions also to some extent incorporate blame attribution and responsibility and obscures how evidence originates and is legitimized. There is only yourself to blame when you 'get injured or die in a fall of ground'. This kind of reification smacks of systemic deception. Such expressions are the 'brittle façade of reifying concepts which obscure and distort our understanding of our reality (Elias, 1978: 15) and 'seduces us into thinking about them as free-standing entities rather than effects produced through precariously balanced figurational patterns of actions and interactions (Chia, 1996: 143). Regular review of disasters, taking into account the causes and eventual impacts will not only further inform future mitigation processes but are effective instruments to foster positive employee relations. We see disaster preparedness strategy as a discourse, subject to all immanent processes of inclusion and exclusion that characterize any discourse (Foucault, 1980). To what extent is the occupational safety project collective? Who benefits from it? Strategies for disaster preparedness or recovery are premised on the logic of collective responsibility and consensus and this is a bit problematic. Prevention, preparedness, response and recovery strategies including public education in the community in which the company operates, provide both employees and general public with safety and peace of mind, thus perpetuating the illusion that risk is controllable or manageable (Goldstein, 1990).

\subsection{Managing Risks or Disasters from the Environment}

$\mathrm{ABC}$ is committed to social development initiatives and engages in, develops and builds community relationships. It takes responsibility for economic, social and environmental issues that impact its people, communities and environments and is involved in a number of community projects in the area. The company also recognizes that business sustainability is realized when an organization ploughs back part of its returns to the community where it is located and operating as part of its strategy to promote socio-economic development. $\mathrm{ABC}$ is also involved in regular public education programs focusing on preparedness and response measures to mitigate the hazards and disasters associated with its operations on the society. Society can be both source and victim of disasters that that affect the organization directly or indirectly. Disaster is a socially interactive phenomenon and public education can interact with and shape disaster. Consider for example the cholera epidemic which engulfed the whole country in 2008. This sounds quite congruent to proactive planning and evens more compelling given the political situation in Zimbabwe. However, this was not good enough in the light of the new legislation on Indigenization which required foreign owned companies to bequeath $51 \%$ of their 
stake to indigenous owners. This has created anxiety among employees. This was one of the unanticipated events which management had not proactively planned for. It was indeed a strategic risk to business sustainability in general and the mining sector in particular. Given the unpredictability of the Zimbabwean government and its knack of predation over the years particularly its handling of the land, mining sector shareholders should have seen it coming one day! According to Ashby's Law of Requisite Variety (Nedopl et al., 2011: 126), 'the organization has to be as complex as its environment to cope efficiently with the external complexity'. The situation was invariably complex and entropic and hence requiring 'post-normal' response or a form of 'organizational improvisation' (Orlikowski, 2002). Despite the controversies and contradictions surrounding legislation on the Indigenization, $\mathrm{ABC}$ recently signed an agreement with the government on the transfer of $51 \%$ shares perhaps to stop anxieties surrounding the issue and any possible disruptions in the operations. Although the Group indicated this was not an ideal outcome (SDR 2012: 75) this was a reasonable response under the circumstances.

\section{Conclusions and Recommendations}

We have observed that the motives for acting 'proactively' and overtly presenting the disaster preparedness or recovery plans as such was both economic and political. Disaster preparedness was perhaps an adaptive methodology for organizational sustainability (AMOS) given the complex and flux nature of these emergencies albeit the unpredictability of the operating environment. This article also argues that these emergencies or disasters or mishaps that occur in the mines were too complex and entropic (Baranger, 2002) and 'wicked' (Goldstein, 1990) to require pro-active planning. Such an approach may limit organization's options for dealing with the irreducible complexity and uncertainty of the environment. Pro-active planning is therefore a mirage that cannot be reached.

The value of all strategies, no matter how brilliant, decays over time. This has led some strategic planners to build planned obsolescence into their strategies (Abell, 1978). Any action or intervention is undertaken in the service of organization's structural coupling without impacting negatively on itself while maintaining a tight internal fit among capabilities, structures and processes. Our analysis is not intended to gloss over the good health and safety performance and production record posted by the company over the years but is only cautious of the possible dangers of presenting plans as purely rational or value-free. Certainly planning is all about power and control and to this end $\mathrm{ABC}$ mine management have been quite effective. Drawing insights from this case study, management led by HR should create and sustain the organization's credibility and trust among crisis stakeholders particularly customers, employees and government. Apart from planning for disaster prevention, preparedness, response and recovery to productivity, overall it is important to protect the company's reputation, brand and value in the market.

When dealing with any complex system, the practitioner should be aware that there is some measure of inherent irreducible uncertainty with complex self-organizing system. The durability of any disaster 'preparedness strategy' lies not on its ability to prevent or prepare for the disasters but present itself in a way that shows corporate commitment to occupational health and safety to all stakeholders including fostering employee trust and confidence. 'Pro-active planning' is a representational device that portrays emergencies as less complex and wicked, reducing them to controllable and manageable entities (Goldstein, 1990). This form of reification and manipulation while appearing unethical inadvertently fosters stakeholder confidence particularly state and employees. Policies and programs in line with international and national regulations and standards are overtly presented as both 'preparedness' and 'recovery' strategies when they are covertly strategic containing figments of deception and manipulation. Some of the elements of these strategies can be analyzed from the view point of strategic use of symbolic expressions for creating consensus with its stakeholders. They are rhetorical tools used to convince audiences that an effective risk management system had been instituted (Browning \& Shelter, 1992).

Scholarly debate on whether or not mining companies are battling with disaster 'preparedness' strategies, disaster 'coping' or response mechanisms or post-disaster 'recovery' planning is likely to rage on for some time and perhaps further research along comparative longitudinal analysis with a larger sample may produce more conclusive results. Although the data collection methods used were sufficiently reliable in helping us achieve our initial objective, over reliance on content analysis of documentary evidence and a few interviews was one of the study's limitations. Further research using more on-site ethnographic techniques such as case narratives or focused group discussions over a longer period of time is recommended.

\section{References}

Baranger, M. (2002). Chaos, Complexity and Entropy-a Physics Talk for Non-Physicians. New England 
Complex Systems Institute. Retrieved from http://www.ncsi.org/projects/baranger/cce

Beck, U. (1992). Risk Society: Toward Reinventing New Modernity. London: SAGE.

Blythe, B. T. (2004). Human Side of Criss Mnagement. Occupational Hazards. Retrieved from http://www.cmaitl.com

Browning, L. D., \& Shelter, J. C. (1992). Communication in Crisis, Communication in Recovery: A Post-modern Commentary on the Exxon Valdze Disaster. International Journal of Mass Emergencies and Disasters, 10(3), 477-498.

Burr, V. (1995). An Introduction to Social Constructionism. London: Routledge. http://dx.doi.org/10.4324/9780203299968

Camillus, J. C. (2008). Strategy as A wicked Problem. Harvard Business Review, 99-106.

Castree, N., \& Braun, B. (2001). Social Nature: Theory, Practice and Politcs. London: Blackwell Publishers.

Chia, R. (1996). Organizational Analysis as Deconstructive Practice. New York: Walter de Gruyter.

Cronon, W. (1995). Uncommon Ground: Towards Reinventing Nature. New York: Norton and Company.

Delery, J. E., \& Doty, D. H. (1996). Modes of Theorizing in Strategic Human Resource Management: Tests of Universalistic, Contingency and Configurational Performance Predictions. Academy of Management Journal, 39(4), 802-835. http://dx.doi.org/10.2307/256713

Derrida, J. (1981). Positions. Chicago: University of Chicago Press.

Dempester, M. B. L. (2000). Symboietic and Autopoietic Systems: A New Distinction for self-orgsnising systems. In Allen, J. K., \& Wilby, J. (Eds.), Proceedings of the World Congress of the Systems and ISSS 2000. Toronto: Ontario.

Elias, N. (1978). What is Sociology? London: Hutchingson.

Fegley, S., \& Victor, J. (2005). Disaster Preparedness Survey Report. Society for Human Resources Management 2005. AlexandrIa, VA.

Fischer. (2001). The Deconstruction of the Command and Control Model: A Post-Modernist Analysis. A Paper Presented at The Annual Meetings of the European Sociological Association. Helsinki: Finland. August-September, 2001. http://dx.doi.org/10.1093/019924264X.001.0001

Fischer, F. (2003). Reframing Public Policy. Oxford University Press.

Foucault, M. (1980). Power/ Knowledge. New York: Pantheon.

Funtowicz, S. O., \& Ravetz, J. R. O. (1993). Science for the Post- Normal Age. Futures, 7(25), 739-755. http://dx.doi.org/10.1016/0016-3287(93)90022-L

Garfinkel, H. (1967). What is Ethnomethodolgy? Polity Reader in Social Theory. Oxford: Blackwell.

Goldstein, B. (1990). The Problem with The Margin of Safety: Toward the Concept of Protection. Risk Analysis, 10(1). http://dx.doi.org/10.1111/j.1539-6924.1990.tb01012.x

Habermas, J. (1982). A Reply to My Critics. In Thompson, J. B., \& Held, D. (Eds.), Habermas: Critical Debates. London: Macmillan.

Hassard, J., \& Parker, M. (1993). Postmodernism and Organizations. London: Sage Publ. Ltd.

Hiles, A. (2004). Business Continuity: Best Practice and Business Continuity Management. Brookfield, CT: Rothstein Associates, Inc.

Lockwood, N. R. (2005). Crisis Management in Today's Business Environment: HR's Strategic Role. 20005 SHRM Research Quarterly. Alexandria, VA.

Lyotard, J. F. (1984). The Postmodern Condition: A Report on Knowledge. Manchester: Manchester University Press.

McCarthy, D. (2003). Complex Systems Thinking and Post-Normal Thinking and Governance: Towards a Critical, reflexive decision making. University of Waterloo.

Mintzberg, H. (1994). The Rise and Fall of Strategic Planning. Boston: Basic Books.

NSSA Annual Statistics Report. (2010). Harare. Zimbabwe.

Nedopil, C., Steger, U., \& Amann, W. (2011). Managing Complexity in Organizations: Text and Cases. New 
York. Palgrave Macmillan.

Neuman, W. L. (2000). Social Research Methods: Qualitative and Quantitative Approaches. Boston: Allyn and Bacon.

Orlikowski, W. J. (2002). Organising Organizational Transformation over Time. In Kamoche, K., MeCunha \& DaCunha, J. (Eds.), Organisational Improvisation (pp.185).

Pettigrew, A. M. (1977). Strategy Formulation as a Political Process. International Studies of Management and Organization, 78-87.

Safety and Health at Work (SHAW). (2012). Harare. Zimbabwe.

Sim, S. (2001). Routledge Companion to Postmodernism. London: Routledge.

Swanepoel, B., Erasmus, B., Van Wyk, M., \& Schenk, H. (2003). South African Human Resource Management: Theory and practice (3rd ed.). Cape Town: Juta.

Ulrich, D., \& Brockbank, W. (2005). The HR Value Proposition. Boston, MA: Harvard Business School Press.

\section{Copyrights}

Copyright for this article is retained by the author(s), with first publication rights granted to the journal.

This is an open-access article distributed under the terms and conditions of the Creative Commons Attribution license (http://creativecommons.org/licenses/by/3.0/). 